\title{
Pre-Flight Dark Forward Electrical Testing of the Mir Cooperative Solar Array
}

Thomas W. Kerslake

Lewis Research Center

Cleveland, Ohio

David A. Scheiman

NYMA, Inc.

Brook Park, Ohio

David J. Hoffman

Lewis Research Center

Cleveland, Ohio

Prepared for the

32nd Intersociety Energy Conversion Engineering Conference cosponsored by AIChE, ANS, SAE, AIAA, ASME, and IEEE Honolulu, Hawaii, July 27-August 1, 1997

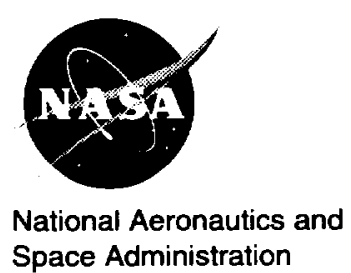




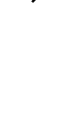




\title{
PRE-FLIGHT DARK FORWARD ELECTRICAL TESTING OF THE MIR COOPERATIVE SOLAR ARRAY
}

\author{
Thomas W. Kerslake \\ NASA Lewis Research Center \\ Cleveland, Ohio 44135 \\ 216-433-5373 (voice) ; 216-433-2995 (fax) \\ David A. Scheiman \\ NYMA Setar Inc. \\ Brook Park, Ohio 44142 \\ 216-433-6756 (voice) ; 216-433-6106 (fax) \\ David J. Hoffman \\ NASA Lewis Research Center \\ Cleveland, Ohio 44135 \\ 216-433-2445 (voice) ; 216-433-2995 (fax)
}

\begin{abstract}
The Mir Cooperative Solar Array (MCSA) was developed jointly by the United States (US) and Russia to provide approximately $6 \mathrm{~kW}$ of photovoltaic power to the Russian space station Mir. After final assembly in Russia, the MCSA was shipped to the NASA Kennedy Space Center (KSC) in the summer of 1995 and launched to Mir in November 1995.

Program managers were concerned of the potential for MCSA damage during the transatlantic shipment and the associated handling operations. To address this concern, NASA Lewis Research Center (LeRC) developed an innovative dark-forward electrical test program to assess the gross electrical condition of each generator following shipment from Russia. The use of dark test techniques, which allow the array to remain in the stowed configuration, greatly simplifies the checkout of large area solar arrays. MCSA dark electrical testing was successfully performed at KSC in July 1995 following transatlantic shipment. Data from this testing enabled engineers to quantify the effects of potential MCSA physical damage that would degrade on-orbit electrical performance. In this paper, an overview of the principles and heritage of photovoltaic array dark testing is given. The specific MCSA dark test program is also described including the hardware, software, testing procedures and test results. The current-voltage (IV) response of both solar cell circuitry and bypass diode circuitry was obtained. To guide the development of dark test hardware, software and procedures, a dedicated FORTRAN computer code was developed to predict the dark IV responses of generators with a variety of feasible damage modes. By comparing the actual test data with the predictions, the physical condition of the generator could be inferred. Based on this data analysis, no electrical short-circuits or open-circuits were detected. This suggested the MCSA did not sustain physical damage that affected electrical performance during handling and shipment from Russia to the US. Good agreement between the test data and computational predictions indicated MCSA electrical performance was amenable to accurate analysis and was well understood.
\end{abstract}

\section{INTRODUCTION}

The objective of the Mir Cooperative Array (MCSA) project was to increase the electrical power available to the 10 -year old Russian space station Mir (Housten et al., 1996). The added power would extend Mir's useful life and support U.S. experiments conducted under the International Space Station (ISS), Phase I United States (US)/Russian program. This objective was met by replacing an existing, degraded photovoltaic array with a new array developed cooperatively by the U.S. and Russia using existing hardware to the maximum extent. The MCSA was launched to Mir by the space shuttle Atlantis during the STS-74 mission in November 1995 and installed on the Kvant-1 module in May 1996. A secondary program objective was to reduce technical risk for the ISS Phase II Program since MCSA performance data are directly applicable to ISS arrays which employ the same US solar array technology.

The MCSA consists of 84 Photovoltaic Panel Modules (PPMs) (Chau and Brisco, 1995) mounted in pairs (end-to-end) in 42 Russian Module Frame Assemblies or panels. Figure 1 is a photograph of the MCSA, shown in the foreground, installed on Mir. The MCSA has an 18-m deployed length, a width of $2.7-\mathrm{m}$, a mass (including deployment mechanism) of $517 \mathrm{~kg}$ and a beginning-of-life power of approximately $6 \mathrm{~kW}$. The MCSA is performing well on-orbit based on the detailed electrical performance data analyzed to date (Kerslake et al., 1997).

Each PPM, shown in Figure 2, is a collection of 80 seriesconnected, $8 \mathrm{~cm} \times 8 \mathrm{~cm}$, silicon solar cells. These cells were originally developed for the Space Station Freedom program and will be used on the ISS arrays. The cells are mounted on a flexible polyimide/glass scrim cloth substrate and connected via a copper flat printed circuit (FPC). A by-pass diode is wired in parallel with every 10 cells. In order to fit the PPM into the existing frames, the five cells at each end of the PPM were shortened by $0.5 \mathrm{~cm}$. The PPMs are wired in parallel groupings of either 6 or 8 to form current generators. There are six generators consisting of 8 PPMs and six generators consisting of 6 PPMs.

\subsection{Motivation for MCSA Dark Testing}

After final assembly in Russia, the MCSA was shipped to the NASA Kennedy Space Center (KSC) in the summer of 1995. Program managers were concerned of the potential for MCSA 
damage during the transatlantic shipment and the associated handling operations. To address this concern, NASA Lewis Research Center (LeRC) developed an innovative dark-forward electrical test program. The use of dark test techniques, which allow the array to remain in the stowed configuration, greatly simplifies the checkout of large area solar arrays. Substantial time and cost savings are realized since no array deployment fixtures and solar simulators are required for testing.

MCSA dark electrical testing was performed at KSC in July 1995 following transatlantic shipment of the MCSA. These data enabled engineers to quantify the effects of potential MCSA physical damage that would degrade on-orbit electrical performance. Armed with this fore knowledge, resource planners could schedule Mir utilization according to the actual MCSA power augmentation that would be provided.

\subsection{Basic Principle of Dark Electrical Testing}

A dark electrical test is done by measuring the forward-biased diode characteristics of an array. A dark diode curve is obtained by applying a series of voltage pulses across a diode string and plotting the current as a function of voltage. Since the diode (solar cell) is forward-biased, current is conducted in the opposite direction than that of the illuminated cell. This configuration reverse biases the bypass diodes.

A standard solar cell string dark diode curve, given by,

$I=I_{o}\left\{\exp \left(V / V_{T}\right)-1\right\}$,

can be transformed into the string illuminated IV curve,

$I=I_{L}-I_{0}\left\{\exp \left(\left[V+R_{s}\right] / A V_{T}\right)-1\right\}-\left\{\left[V+R_{s}\right] / R_{s h}\right\}$,

by shifting the curve by $I_{L}$ (the illuminated current or short-circuit current) and by adding the solar cell lumped series resistance

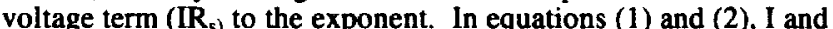
$V$ are the respective current and voltage values, $I_{0}$ is the reverse saturation current, $V_{T}$ is the thermal voltage dependent on both temperature and the semiconductor material band gap, $R_{\mathrm{sh}}$, is the solar cell shunt resistance (assumed to be very large) and A is a constant. Values for $I_{0}, R_{s}$ and $A$ were determined for each PPM in the MCSA based on illuminated IV tests. Voltage dependent $\mathrm{R}_{\mathrm{s}}$ data were obtained from PPM-level illuminated and dark forward test data via the dark curve method (Imamura, 1970).

By comparison with a baseline dark diode curve, subsequent dark diode curves can be measured to monitor the condition of the solar array during acceptance testing and ground handling operations. The final dark diode IV curve measured prior to launch can then be converting to an illuminated IV curve for calculating on-orbit solar array electrical performance. The same dark forward test techniques can also be used to measure the bypass diode string IV response. Dark test techniques were successfully used on the Hubble Space Telescope Arrays (Preitnacher et al., 1991 and Gerlach, 1995) as well as on the Skylab Apollo Telescope Mount (ATM) solar arrays (Crabtree, 1972 and Crabtree, 1995 and Imamura, 1970). A related capacitance test technique (Mueller et al., 1996) has also been proposed to check for solar cell string damage.

\section{MCSA DARK TEST OBJECTIVE}

The primary objective of this testing was to determine whether any gross degradation existed in the electrical power generation capability of the MCSA at KSC prior to launch. This test was performed to assure program management that the MCSA suffered no damage during handling and shipment from Russia that would significantly degrade electrical performance. In this context, damage was defined by open-circuits and/or shortcircuits in the PPMs, by-pass diodes and current generator wiring.

\section{TEST FACILITY AND PERSONNEI}

The MCSA dark electrical tests were performed at the KSC Space Station Processing Facility Intermediate Bay. The bay area is a level 4 Clean Work Area with temperatures maintained at $21.7^{\circ} \mathrm{C}+/-3.3^{\circ} \mathrm{C}$. The MCSA was mounted in the base of its shipping container which was placed on an air-bearing pallet in close proximity to the bay's electrical service outlets (see Figure 3). The test conductors were from LeRC with test support personnel provided by the Rocket Space Corporation-Energia (RSC-E).

\section{TEST EQUIPMENT}

\subsection{Hardware}

The test hardware consisted of a power supply, a custom made switch box, digital volt meters (DVMs), a personal computer and cabling. A schematic of the test setup is provided in Figure 4. The power supply, switch box, and MCSA generator under test formed the test circuit while the computer and DVM's were peripheral devices. After all connections were made, the computer controlled connections to each generator, the direction of the current, current limits, voltages of the power supply, display of data, and storage of the data. This was done to avoid any chance of operator error at the test site and to further maintain the integrity of the flight hardware.

Power was provided by a Sorensen DCS60-50-M9A variable DC laboratory grade power supply. The unit had voltage and current regulation was IEEE-488 programmable with many additional protection features. The output could be shutdown by software, switching from voltage control to current control or vice versa (called folding), or by the variable over-voltage protection.

The switch box was a 12-channel, custom-made unit which contained digitally controlled relays, additional protection circuitry, flight connectors, connections for computer and DVMs, and a shunt resistor. The relays switched in and out each generator, changed the power supply polarity, and switched connections to each temperature sensor. All wiring and relays were rated for 20 amps. Each generator was connected to the power supply through relays on both the positive and the negative leads. The relays also reversed the polarity of the power supply so the bypass diodes could be forward biased. All circuits were open with no power to the relays (manual operation is not possible). Maximum current was limited by a fuse and additional circuitry provided over-voltage protection.

Switch box mating connectors, provided by RSC-E, were built into the box and hard wired to provide access to all 12 generators through a single male (positive) and female (negative) connector. These two individual connectors mated directly with the flight test cable connectors of the array provided by RSC-E. This cable interfaced the switch box to the MCSA X1-X4 flight connectors (see Figure 5). Four additional connectors provided 4-wire resistance measurement of the four Rosemount Aerospace Inc. 118MF-100-A platinum Resistance Temperature Device (RTD) sensors mounted on the inactive side of PPMs in generators 1,2 and 3. RTD test cables were provided by RSC-E to interface the switch box with the MCSA X144/90 flight connector. RTD resistance values were converted to temperature using an equation derived from calibration data. The accuracy of the RTD temperature measurements was within $0.1^{\circ} \mathrm{C}$.

To measure channel current, a $0.01 \mathrm{ohm}$ resistor was placed in series with the positive lead of the power supply (prior to the polarity relays). Additional DVM connectors were provided to facilitate channel current and voltage measurements as well as RTD 4-wire resistance measurements. Newly calibrated Fluke 45 DVMs with auto-ranging and 5+ digits readout accuracy were used to measure output current and voltage with an accuracy of 
\pm 0.005 amps and \pm 0.010 volts, respectively. $R T D$ resistances were measured using a Hewlett Packard HP34401A meter. These meters were remotely controlled through an IEEE-488 interface. The computer was a standard IBM-486 compatible clone with a standard IEEE-488 card and digital I/O card. The I/O card had 24 digital V/O lines which were set up as outputs to control each relay in the switch box. All cabling was gender sensitive and different for each type of connector used.

\subsection{Software}

The software and hardware were developed to minimize the operator error once the set up was complete. The software was written in QuickBasic 4.5 and operated in that environment to allow for any last minute modifications. Once the equipment was turned on and the program running, all devices were controlled by the operator. The software was improved as the result of experience gained by testing PPM-like solar cell strings. The computer was used to minimize the power supply voltage pulse time to minimize array heating.

The power supply was programmable with both voltage and soft current limits. The current limit was set based on the maximum power supply current. If this limit was reached, the voltage would then drop to maintain that current and the power supply would switch to current control. The power supply could also be programmed to shutdown when the mode of control switched from constant voltage to constant current. All of the voltage points and their current limits were predetermined from theoretical modeling and testing done on Photovoltaic Array Environmental Protection (PAEP) Program panels (Bilger, 1989) available at LeRC. These panels were utilized since they contained solar cells and interconnect wiring nearly identical to that used on the MCSA.

For each generator, a voltage point, theoretical current, and current limit were read from a data file. A typical IV curve will contain 15-20 data points. Once retrieved, these data points were plotted on the screen as solid lines. The power supply was then programmed with the voltage point and current limit and the output current and voltage were measured. This was plotted as a dot on the screen, if the current limit was hit then the power supply would shutdown and the operator would be asked to continue. At any time during the IV curve the program can be aborted and all outputs shut down. Subroutines were written to detect communication problems between the power supply and DVMs and to shut down the power supply.

The software program started by first asking for a time and room temperature. Then a menu appeared containing the four test options that the operator could choose from: (1) system check on a sample circuit, (2) forward bias of generators, (3) forward bias of bypass diodes, and (4) reading of temperatures. The first three test options each asked for the generator number (default is 2) to be tested. Then the predicted IV curve and current limits were displayed. This defined the approximate envelope that the actual data should fall within. The array forward bias pulse duration was set to be just long enough to allow power supply transients to settle and to allow the DVMs to get a reading. The temperature of all 4 RTDs was updated after each reading. All data were stored automatically in an indexed file. The operator had the option to retest, abort, continue to next generator, run a range of points at higher resolution, or select a specific generator to test. If any point of the IV curve exceeded the current limit in software, the operator was given the opportunity to stop or continue. If temperature test option was selected, all 4 RTD temperatures were displayed along with the input value of room temperature ascertained by an independent measurement.

\section{TEST PROCEDURES}

Dark electrical tests were first performed on a 400 cell PAEP panel which was divided into 5 parallel-connected, 80-cell strings (Kerslake, 1995). This testing verified test equipment operation (excluding the switch box) and test procedures to minimize the risk of MCSA damage as a result of the dark testing. Testing also served to validate the computational model used to predict dark IV response and demonstrate that simulated faults introduced into the test solar cell strings could be successfully detected. Additionally, the solar cell strings were purposely forwardbiased to produce current levels twice that of the cell short-circuit current with no resulting measurable damage. The strings were also tested under ambient room lighting conditions and nearly complete darkness to quantify stray light impacts. Stray light had a negligible impact on measured current levels.

\subsection{System Checkout at KSC}

All wiring and connections were visually inspected prior to energizing the power supply. Relays were visibly checked to ensure that none were stuck open or closed and their switching operation was confirmed. Proper system wiring and operation were verified by running a dark diode curve on a sample dioderesistor circuit which was temporarily connected to the switch box output connector. All 12 switch box channels were tested in this manner for both forward and reverse biasing.

\subsection{Current Generator Forward Bias Test}

The MCSA was first cloaked with a black cloth. This was done to minimize the effects of stray room light that could conceivably impinge on MCSA solar cells through the spaces between adjacent panels. The switch box was then connected to the MCSA generators and RTDs. Generator 2 was first to be tested since it afforded two temperature measurements to monitor cell heating effects. For the generator under test, each data point was plotted on the computer monitor along with the theoretical IV curve and current limits. The power supply was set to a bias voltage and current limit. This voltage was applied to the generator for a period of 500-750 milliseconds. During this period, the channel current and voltage were read by the DVMs. Power was then disconnected and the point is plotted on the screen along with any anomaly flags. There were approximately 15-20 data points measured to generate a good representative diode IV curve. The voltage applied ranged from 5 to 58 volts so that resulting currents would remain below the illuminated shortcircuit current level of each generator $(\sim 15$ amps and $\sim 20$ amps for 6-PPM generators and 8-PPM generators, respectively). Actual currents did not exceed 14 amps due to higher than anticipated series resistance in the switch box.

\subsection{By-pass Diode Forward Bias Test}

The by-pass diodes were tested in much the same way as the solar cell strings of the each generator. There were 8 seriesconnected by-pass diodes on each PPM thus permitting low voltage test levels. The voltage applied ranged from $0-13$ volts with current levels similar to those from generator tests. The temperature of these diodes could not be monitored.

\section{TEST RESULTS}

\subsection{Current Generator Forward Bias Test}

Generator dark forward test data are plotted in Figure 6. Current and voltage measurements were taken at the output terminals of the power supply. Voltage at the PPMs will be less due to voltage drops in the switch box, cables and MCSA FCC wiring. 
For each generator, two consecutive tests were conducted. The dark IV curves were generally repeatable to within 0.2 amps. This indicates the data sets were free from spurious data points and that testing did not affect the IV performance of the generators. Current limits, based on pre-test predictions, were not exceeded during testing at meaningful current levels, i.e. above $\sim 0.5$ amps. Therefore, preemptive power supply shut downs were not required. Solar cell heating during a test was less than $0.5^{\circ} \mathrm{C}$.

Current levels for 6-PPM generators were consistent within \pm 0.4 amps and 8-PPM generator current levels were consistent within \pm 0.5 amps. This data consistency between similar generators indicates no PPM-level short-circuits or open-circuits are present. If such conditions existed, generator current levels would differ by more than 2 amps (see Section 7.2). The small current differences between similar generators can be attributed to individual PPM IV characteristics, individual FCC lengths (and electrical resistance), and the generator panel wiring layout ( 2 or 4 PPMs wired per FCC). Dark IV curves for generators 2 and 12 were also measured with the facility lights off. This data generally matched earlier results within 0.1 amps. This confirmed that facility lighting had no significant effect on the measured generator dark IV curves.

\subsection{By-pass Diode Forward Bias Test}

By-pass diode forward bias test data are also plotted in Figure 6. Current and voltage measurements were taken at the output terminals of the power supply. Voltage at the by-pass diodes will be less due to voltage drops in the switch box, cables and MCSA FCC wiring.

For each generator, two consecutive tests were conducted. The dark IV curves were generally repeatable to within 0.3 amps. This indicates the data sets were free from spurious data points and that testing did not affect the IV performance of the generators. As in the generator tests, pre-test current limits were generally not exceeded during testing. By-pass diode heating could not be measured during dark testing but was expected to have minimal effect on the results.

Current levels for 6-PPM generators were consistent within \pm 0.3 amps and 8-PPM generator current levels were consistent within \pm 0.5 amps. This data consistency between similar generators indicates multiple PPM-level short-circuits or opencircuits are not present. The by-pass diode forward test is not capable of detecting a single diode short-circuit or open-circuit on an individual PPM within a generator.

If multiple diode shorts or opens existed, generator current levels would differ by more than 1-2 amps (see Section 7.2). The small current differences between similar generators can be attributed to individual PPM by-pass diode IV characteristics, individual FCC lengths (and electrical resistance), and the generator panel wiring layout ( 2 or 4 PPMs wired per FCC).

\section{DATA ANALYSIS}

\subsection{Dark Test Computer Code}

7.1.1Current Generator Forward Bias IV Predictions. A dedicated FORTRAN computer code was written to predict the MCSA dark IV response. The computational methodologies were based on those from the LeRC electric power system analysis code SPACE (Hojnicki et al., 1993). The theory relating illuminated and dark forward IV curves was taken from Imamura and Portscheller (1970) and is discussed in section 1.2. The code ran on a HP Apollo Series 400 work station at LeRC. Typical code execution times were about 1-2 minutes to analyze all 12 generators. During tests at KSC, a PC version of the code was run in real time on an IBM486-50 Notebook computer. Notebook execution times were on the order of 10-15 minutes.
For the generator forward test predictions, the code calculated the generator dark current level at the specified power supply terminal voltage. For each generator and at each voltage point, the code executed nested iterations to solve for: generator current, panel current, PPM dark voltage, PPM equivalent illuminated voltage, PPM solar cell lumped series resistance and PPM equivalent illuminated current. The convergence criteria were: generator current $(0.0001$ amps), panel current $(0.00001$ amps), PPM illuminated voltage ( 0.00001 volts) and PPM illuminated current $(0.000024$ amps). The code used the following input data: ambient temperature, measured PPM IV curves from flash tests, measured short cell short-circuit current reduction factor, MCSA wiring connectivity, measured FCC resistance, measured flight hardware and test cable resistances, measured PPM lumped series resistance vs. illuminated voltage and measured witch box channel resistances. All resistance and IV data were temperature corrected. Code tabular and graphical outputs include for each generator: generator current vs. terminal voltage, PPM dark current and voltage vs. terminal voltage and PPM illuminated current and voltage.

7.1.2 By-pass Diode Forward Bias IV Predictions. By-pass diode forward IV response was calculated using the code described above. The PPM IV curves were replaced by a standard diode equation. The diode equation constants were chosen to fit lot-average, by-pass diode IV data provided by the vendor.

\subsection{Impact of MCSA Damage Modes}

Prior to the MCSA dark test, the above code was run to quantify the effect of various damage modes on generator current level. Results are shown in Table 1. A current level difference of $\sim 1$ amp was considered the threshold for meaningful detection of a damage mode.

Results indicate the dark forward testing methods are capable of detecting broken conductors and shorted by-pass diodes. Due to the parallel connection of multiple PPMs, generator level dark forward testing is not able to detect isolated, minor damage such as an open-circuited by-pass diode. However, this situation is acceptable since the minor damage modes have little impact on the MCSA illuminated performance.

\subsection{Comparison of Computational and Experimental Results}

The measured current values were compared against pre-test and post-test predictions for all generators. Pre-test predictions were based on some inputs and modeling techniques that were preliminary. For example, the test cable resistance was not known until it was measured at KSC just prior to dark testing. Post-test predictions incorporate the latest values for input parameters and the most complete modeling. Up-dates to the analysis input parameters included: resistance of test cables $1,2,3$ $(0.0202 \Omega$ to $0.0336 \Omega)$ and ambient temperature $\left(22^{\circ} \mathrm{C}\right.$ to $\left.24^{\circ} \mathrm{C}\right)$. Up-dates to the modeling included: adding a switch box voltage drop calculation, removing the PPM FPC resistance (intrinsic to PPM IV data) from final IV computation point when the dark current is equal to the short-circuit current and improving the bypass diode IV model from a single exponential to a double exponential type of model. The primary impact of these up-dates on the predictions came from modeling the switch box voltage drop.

7.3.1 Current Generator Forward Bias Test. Test data are plotted against pre-test and post-test predictions for generator 12 (located at the MCSA tip) in Figure 7. The temperature of the MCSA throughout the test period was approximately $24^{\circ} \mathrm{C}$. The comparison of measurements with pre-test predictions was fairly good for all generators and generally improved with increasing generator number. The comparison showed the slope of the IV curve at high voltages was over-predicted. This suggested that 
the current generator test circuit series resistance was higher than predicted. The magnitude of over-prediction, however, steadily decreased with increasing current generator number.

The cause for added series resistance was found to be the switch box. The measured resistance between the voltage sense point and the output connector was $\sim 0.3 \Omega$ for generator 1 to $\sim 0.1 \Omega$ for generator 12 . When properly accounting for the switch box voltage drop, the agreement between generator IV data and predictions was very good, i.e. generally well less than 1 amp.

7.3.2 By-pass Diode Forward-Bias Test. By-pass diode test data are plotted in Figure 8 against the pre-test and post-test predictions at a temperature of $24^{\circ} \mathrm{C}$. Like the current generator data-prediction comparison, the by-pass diode forward dataprediction comparison showed fairly good agreement between the data and pre-test predictions for all generators. After implementing the revisions listed in section 7.3, the agreement between the data and computations was very good.

\section{CONCLUDING REMARKS}

The primary test objective was met: dark forward IV data were successfully gathered and used to assess the gross electrical condition of each current generator. Based on these data, MCSA generator circuitry appears normal and consistent with pre-test expectations. No electrical short-circuits or open-circuits were detected for any of the generators. Given proper input values, computational methods can accurately forecast array dark IV response. Comparing computation forecasts with measured data provides a viable method for detecting array damage. The dark forward data also could provide an indirect method for baselining array illuminated IV performance prior to launch without deploying the array. This affords significant cost and schedule savings by eliminating ground support hardware necessary to deploy and illuminate large area arrays.

As a means for schedule risk reduction, the ISS Program Office has commissioned a feasibility study for dark testing ISS photovoltaic arrays. Such testing could be performed at KSC as part of the regiment of integration, assembly and checkout test activities to be performed on the ISS port side "P6" photovoltaic module in 1998. This study is in process.

\section{REFERENCES}

Bilger, K. M., et al., 1989, "Photovoltaic Array Environmental Protection Program," 24th Intersociety Energy Conversion Engineering Conference Proceedings, Vol. 1., p. 361-369.

Chau, M. T. and Brisco, H. N., 1995, "Elevated Temperature

Testing of Mir 1 Cooperative Solar Array Photovoltaic Panel Module," IECEC paper no. AP-206, p. 357-362.

Crabtree, W. L., 1972, "The Use of the Solar Cell Dark Characteristic for Checkout of Large Area Solar Arrays," NASA Marshall Space Flight Center, Res. Achievements Rev., Vol Report no. 4, p. 29-35.

Crabtree, W. L., 1995, personal communication, NASA Marshall Space Flight Center.

Gerlach, L., 1995, personal communication, European Space

Research and Technology Center, Noordwijk, The Netherlands.

Hoffman, D. J. and Scheiman, D. A., 1996, "Mir Cooperative

Solar Array Project Accelerated Life Thermal Cycling Test," NASA TM-107197.

Hojnicki, J. S., et al., 1993, "Space Station Freedom Electrical Performance Model," 28th Intersociety Energy Conversion Engineering Conference Proceedings, Atlanta, Georgia.

Housten, S., et al., 1996, "The Mir Cooperative Solar Array Project," 47th Intersociety Astronautical Congress, paper no. IAA-96-IAA.6.1.106, Beijing, China.
Imamura, M. S., et al., 1970, "Solar Cell Dark I-V Characteristics and Their Applications," IECEC paper no. 709129, p. 10-38 through 10-45.

Imamura, M. S. and Portscheller, J. I., 1970, "An Evaluation of the Methods of Determining Solar Cell Series Resistance," IEEE 8th Photovoltaic Specialists Conference, Seattle, Washington, p. 102-109.

Kerslake, T. W., 1995, "Final PAEP Panel Dark Test I-V Curve Data and Predictions," NASA LeRC internal report IBR PS-448 Rev A.

Kerslake, Thomas W., et al., 1997, "Mir Cooperative Solar Array Flight Performance Data and Computational Analysis," 32nd Intersociety Energy Conversion Engineering Conference Proceedings, paper no. 97235, Honolulu, Hawaii.

Mueller, Robert L., et al., 1996, "Capacitance Test For Solar Cells," NASA Tech Brief, Vol. 20, No. 7, Item \#64.

Preitnacher, H., et al., 1991, "Dark Forward Current Measurements of Solar Arrays," European Space Power Conference, Florence, Italy, p. 765-770.

Skor, Michael and Hoffman, David J., 1997, "Mir Cooperative Solar Array Project Overview," 32nd Intersociety Energy Conversion Engineering Conference Proceedings, paper no. 97248, Honolulu, Hawaii.

\begin{tabular}{|c|c|c|c|}
\hline Damage Mode & $\begin{array}{l}\text { Generator } \\
\text { Test (GT) }\end{array}$ & $\begin{array}{l}\text { By-pass Diode } \\
\text { Test (BPDT) }\end{array}$ & $\begin{array}{l}\text { Detectable? } \\
\text { GT/BPDT }\end{array}$ \\
\hline $\begin{array}{l}\text { By-pass Diode Shorts } \\
1 \text { on } 1 \text { PPM per GS } \\
2 \text { on } 1 \text { PPM per GS } \\
1 \text { on each PPM per GS }\end{array}$ & $\begin{array}{l}\text { IV Shift Left } \\
\sim 1 A \odot 48 V \\
-2 A \bigcirc 42 V \\
-7 A \bigcirc 50 V\end{array}$ & $\begin{array}{l}\text { IV Shift Left } \\
-0.5-1 A \odot 12 V \\
-1-2 A \oplus 12 V\end{array}$ & $\begin{array}{l}\text { maybe/ no } \\
\text { yes / yes } \\
\text { yes / yes }\end{array}$ \\
\hline $\begin{array}{l}\text { By-pass Diode Opens } \\
1 \text { on } 1 \text { PPM } \\
1 \text { on Each of } 2 \text { PPMs }\end{array}$ & $\begin{array}{l}\text { No effect } \\
\text { No effect }\end{array}$ & $\begin{array}{l}\text { IV Shift Right } \\
\sim 0.1 \mathrm{~A} \oplus 12 \mathrm{~V} \\
-0.1-3 \mathrm{~A}: 12 \mathrm{~V}\end{array}$ & $\begin{array}{l}\text { no / no } \\
\text { no/ maybe }\end{array}$ \\
\hline $\begin{array}{l}\text { Open Sub-module } \\
\text { Interconnect or } \\
\text { Conductor Between } \\
\text { PPM and FCC }\end{array}$ & $\begin{array}{l}\text { IV Shift Right } \\
\sim 2.5 A @ 60 V \\
\text { per PPM } \\
\text { affected }\end{array}$ & No effect & yes / no \\
\hline $\begin{array}{l}\text { Open FCC Conductors } \\
\text { Opens } 2 \text { PPMs } \\
\text { Opens } 4 \text { PPMs }\end{array}$ & $\begin{array}{l}\text { IV Shift Right } \\
5 A-60 \mathrm{~V} \\
10 \mathrm{6} 00 \mathrm{~V}\end{array}$ & $\begin{array}{l}\text { IV Shift Right } \\
\sim 0.1-3 A-12 V \\
-2-7 A \odot 12 V\end{array}$ & $\begin{array}{l}\text { yes/maybe } \\
\text { yes / yes }\end{array}$ \\
\hline 1 Open FCC Conductor & $-0.5 A \odot 54 V$ & $-1 A \cdot 12 V$ & no / no \\
\hline 1 Crushed Cell & No effect & No effect & no / no \\
\hline
\end{tabular}

Table I. IV Performance Impact of MCSA Damage Modes 


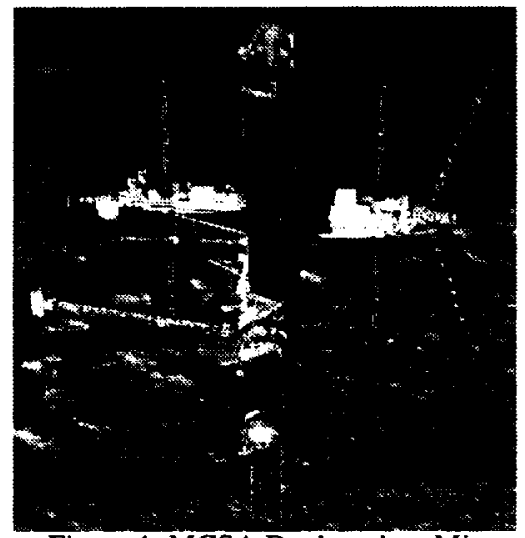

Figure 1. MCSA Deployed on Mir

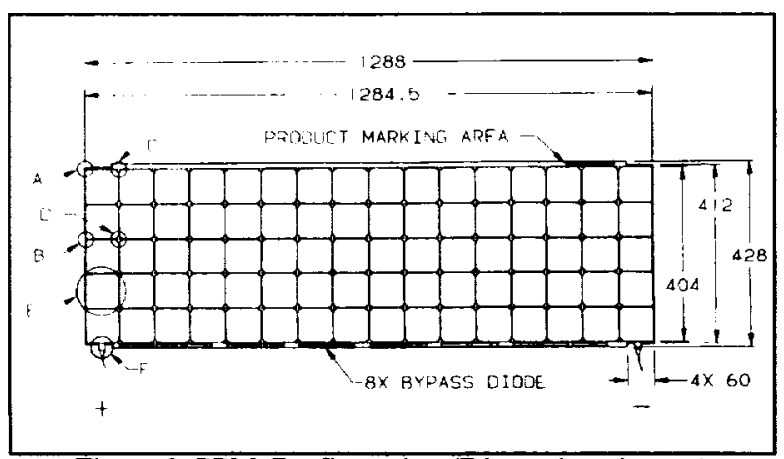

Figure 2. PPM Configuration (Dimensions in $\mathrm{mm}$ )

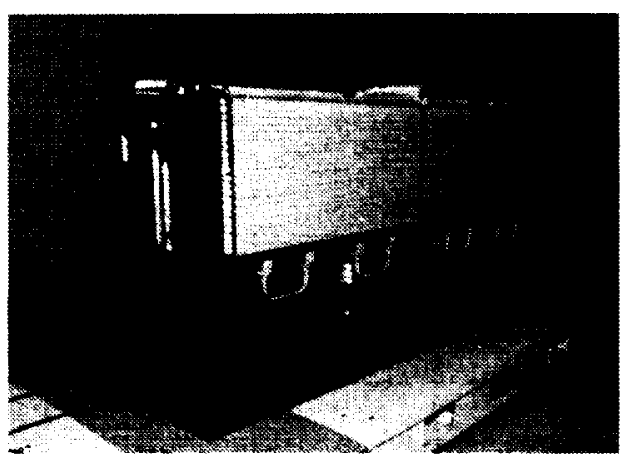

Figure 3. MCSA During Dark Tests at KSC

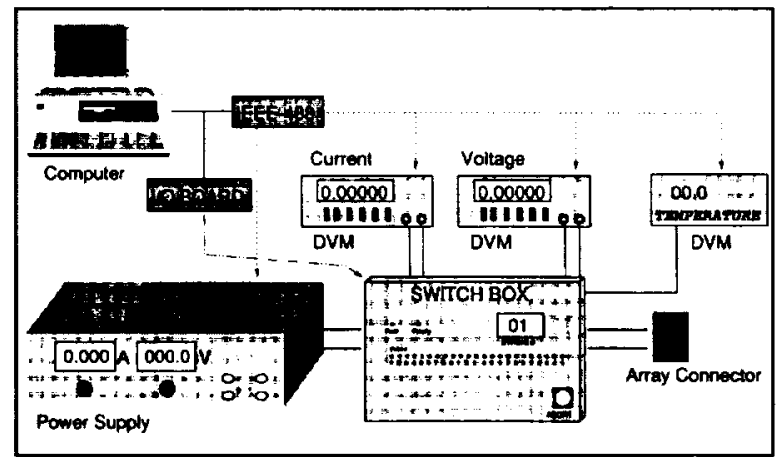

Figure 4. Test Equipment Schematic

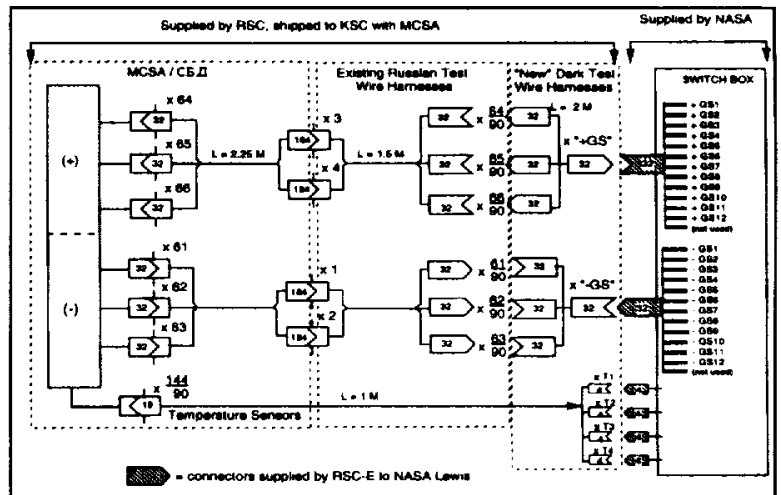

Figure 5. MCSA Flight and Test Cable/Connector Diagram

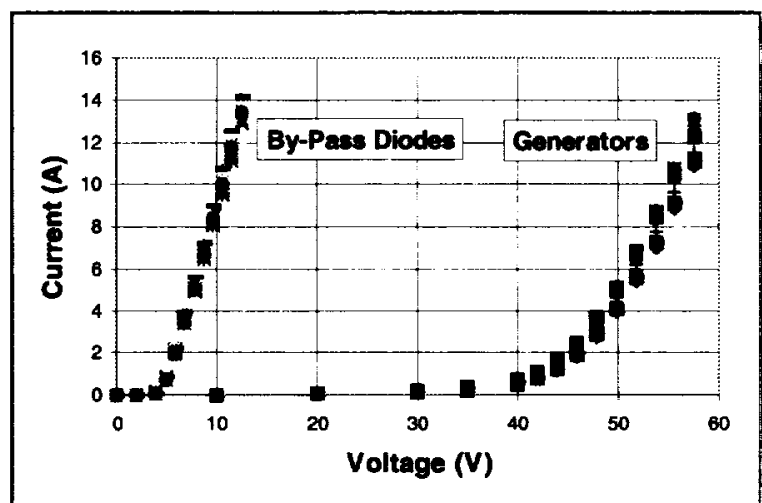

Figure 6. Generator and By-pass Diode Forward-Bias IV Test Data

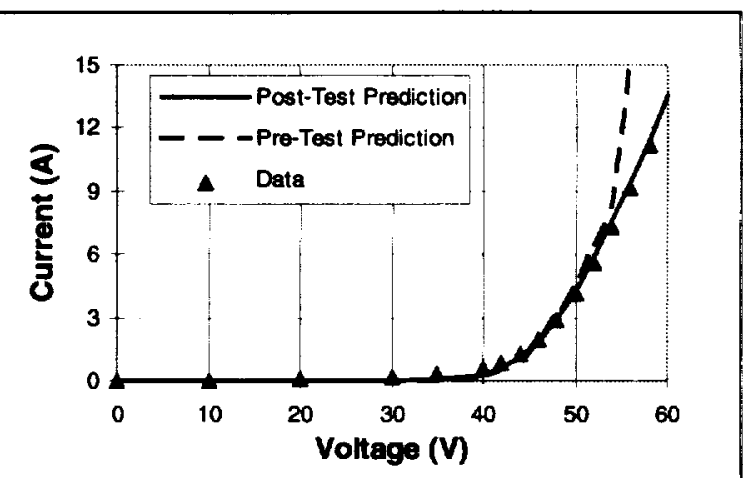

Figure 7. Generator 12 Dark IV Predictions vs. Test Data

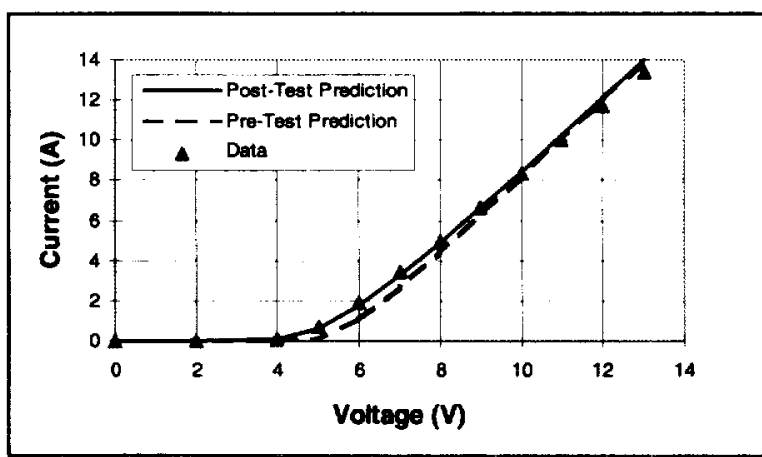

Figure 8. Generator 12 By-pass Diode IV Predictions vs. Test Data 
. 


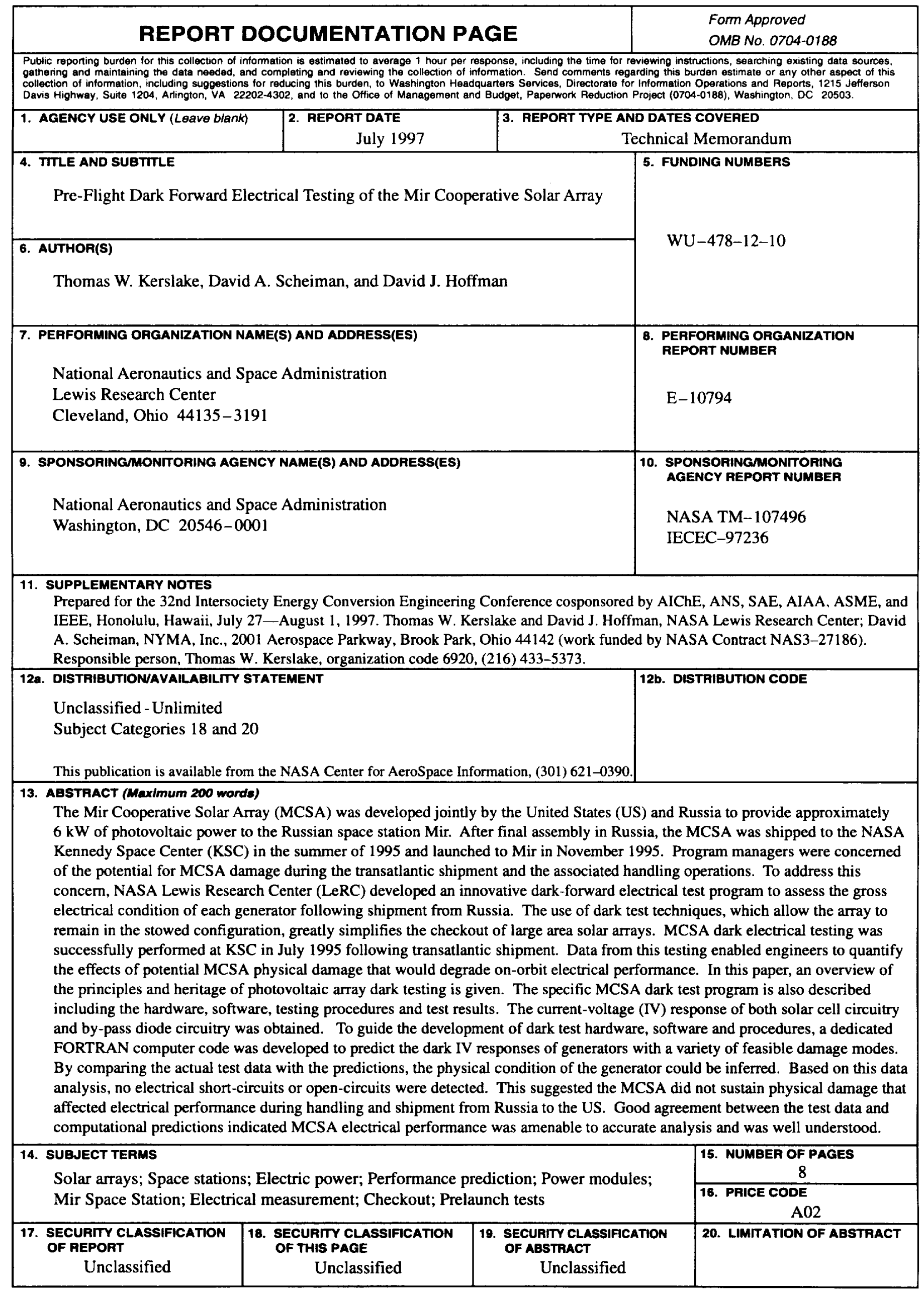

NSN 7540-01-280-5500 